\title{
Cervical Perineural Cyst Masquerading as a Cervical Spinal Tumor
}

\author{
Vijay P Joshi ${ }^{1}$, Atul Zanwar ${ }^{2}$, Anuradha Karande ${ }^{3}$, Amit Agrawal ${ }^{4}$ \\ ${ }^{1}$ Department of Neurosurgery, Ashwini Sahakari Rugnalaya and research center, Solapur, Maharashtra, India \\ ${ }^{2}$ Ashwini Sahakari Rugnalaya and Research Center, Solapur, Maharashtra, India \\ ${ }^{3}$ Department of Anesthesia, Ashwini Sahakari Rugnalaya and research center, Solapur, Maharashtra, India \\ ${ }^{4}$ Department of Neurosurgery, Narayna Medical College Hospital, Nellore, India
}

Tarlov (perineural) cysts of the nerve roots are common and usually incidental findings during magnetic resonance imaging of the lumbosacral spine. There are only a few case reports where cervical symptomatic perineural cysts have been described in the literature. We report such a case where a high cervical perineural cyst was masquerading as a cervical spinal tumor.

Keywords: Tarlov's cysts; Perineural cyst; Spinal cyst; spine; Cervical spine

\section{Introduction}

Tarlov (perineural) cysts of the nerve roots were first described in 1938 [1] and are common and usually incidental findings during magnetic resonance imaging of the lumbosacral spine [2-4]. There are only a few case reports where cervical symptomatic perineural cysts have been described in the literature [5-7]. We report such a case where a high cervical perineural cyst was masquerading as a cervical spinal tumor.

\section{Case Report}

A male patient presented with mild ill-defined neck pain and progressive weakness of all four limbs of six months duration. He had difficulty in walking and holding objects in both upper limbs. There was no history of headache, cough, difficulty in speech or difficulty in swallowing. Bowel and bladder functions were normal. His general and systemic examination was unremarkable. Higher mental functions and cranial nerves were normal. There was increased tone in the upper and lower limbs. Motor power was grade $4+/ 5$ in all groups. There was weakness of bilateral hand grip. Planters were bilateral extensor. Magnetic resonance imaging (MRI) of the cervical spine revealed a large well-defined cystic lesion pushing the cord to the right at the $\mathrm{C} 1-\mathrm{C} 2$ level, that was hypointense on $\mathrm{T} 1 \mathrm{~W}$ images and hyperintense on $\mathrm{T} 2 \mathrm{~W}$ and fluidattenuated inversion recovery sequence images with peripheral enhancement after contrast administration (Figs. $1,2)$. Based on the imaging findings, a diagnosis of cystic schwannoma was suspected. The patient underwent CC2 laminectomy. The lesion was located near the dorsal root ganglion of $\mathrm{C} 2$; once the lesion was opened, clear fluid came out of the lesion. The cyst could be excised completely while keeping the nerve root intact. Histopathological examination revealed inflamed layers of meninges and the presence of neural elements (Fig. 3).

Received Dec 4, 2012; Revised Aug 4, 2013; Accepted Aug 8, 201

Corresponding author: Amit Agrawal

Department of Neurosurgery, Narayna Medical College Hospital, Chinthareddypalem, Nellore-524003, Andhra Pradesh, India

Tel: +91-8096410032, E-mail: dramitagrawal@gmail.com 
The patient improved after surgery and was doing well at follow-up.

\section{Discussion}

Tarlov cysts (perineurial cysts) are defined as cysts formed within the nerve root sheath at the dorsal root ganglion [8], and most of them are clinically insignificant $[1,7,9]$. The estimated incidence is approximately $5 \%$ (symptomatic cases are rare, constituting less than $1 \%$ of the total) [10], and on MRI it has been estimated that Tarlov cysts are present in $4.6 \%$ to $9 \%$ of the population, with an estimated $10 \%$ becoming symptomatic at some point during life [10]. Commonly Tarlov cysts are found in the lumbo-sacral region $[1,4,7,9]$, with the $\mathrm{S} 2 / \mathrm{S} 3$ nerve roots most commonly affected [4,7]. The exact etiology of perineurial cysts remains unclear. It was proposed that hemosiderin deposition caused by blockage of the venous drainage of the perineurium and epineurium after local trauma can lead to the development of these cysts [11], or that congenital arachnoid proliferation along the exiting nerve roots can result in the formation of perineurial cysts [12], and it has also been suggested that the ballvalve mechanism is responsible for the entry of cerebrospinal fluid into the cyst during systolic pulsations but that the cerebrospinal fluid is unable to exit through the same portal during diastole [7,9,11]. A histological characteristic of the Tarlov cyst is the presence of nerve fibers
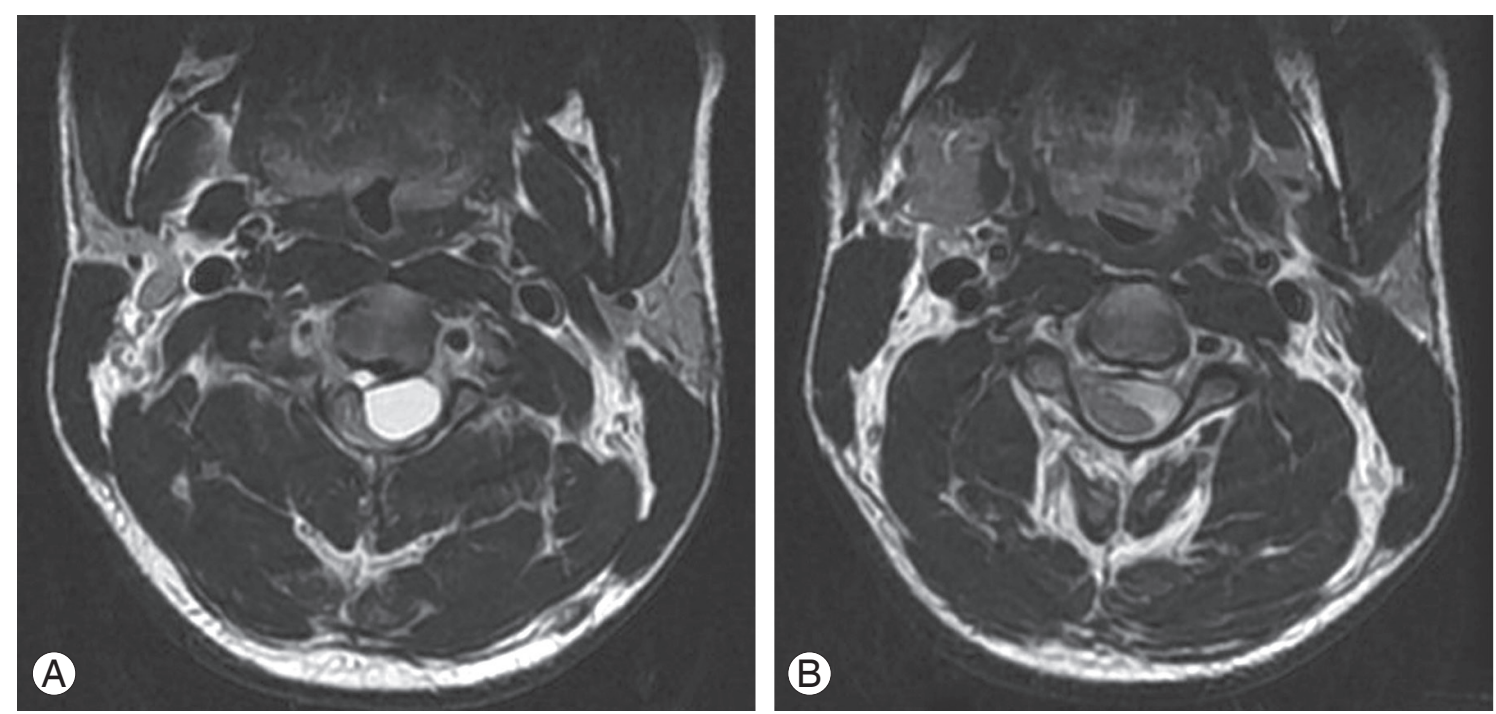

Fig. 1. Magnetic resonance imaging of the cervical spine axial T2 weighted images showing a large cystic lesion pushing the cord to the right. (A) T2 weighted and (B) fluid-attenuated inversion Recovery sequence images.
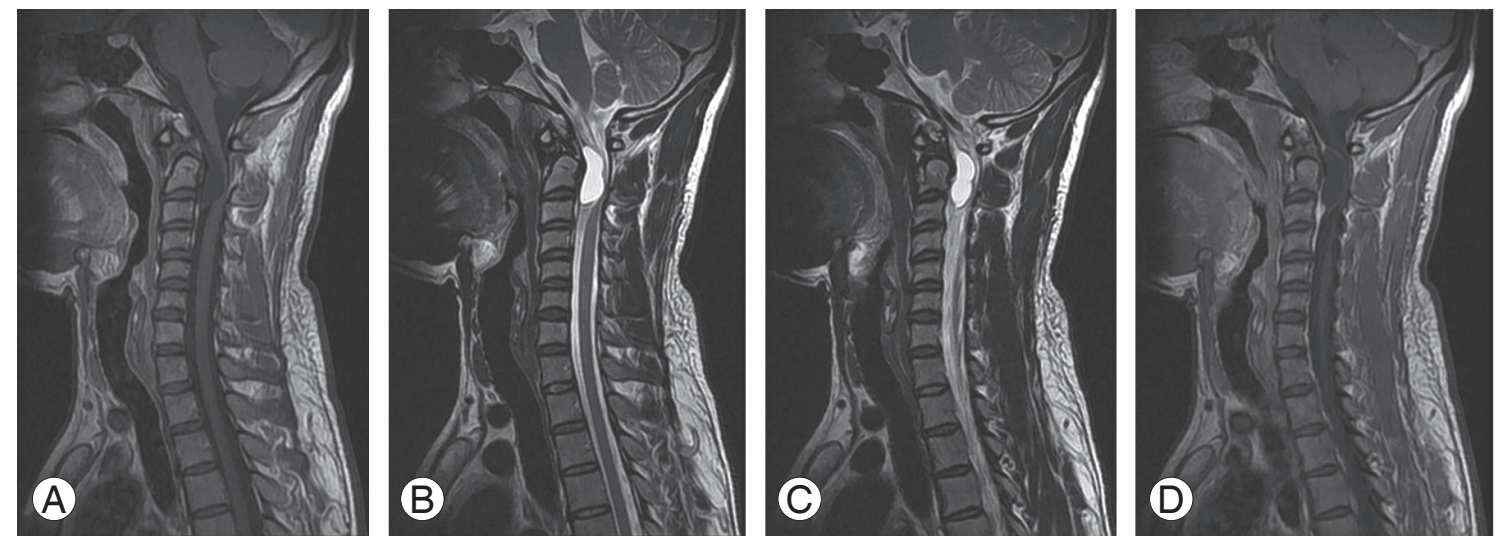

Fig. 2. Magnetic resonance imaging cervical spine sagittal images showing an isointense lesion on the T1W image (A), becoming hyperintense on T2W (B) and fluid-attenuated inversion recovery sequence images (C), with peripheral rim of enhancement after contrast administration (D). 
in the cyst wall [1,7-9]. Symptomatic Tarlov cysts are rare and clinical symptoms depend on the location of the cyst; symptoms range from backache, perineal pain or sciatica to overt cauda equina syndrome [4,9]. The symptoms are mostly exacerbated by maneuvers that elevate the intraspinal cerebrospinal fluid pressure, including coughing, walking, change of posture, and the Valsalva maneuver [13]. In the present case, the patient had features of compressive cervical myelopathy because of the location of the cyst. MRI is an effective way to investigate these lesions as it will provide better details such as showing the extent of the lesion and its relationship to surrounding structures $[3,6,10]$. For symptomatic cases microsurgical excision of the cysts is curative and has a good outcome
$[3,4,7]$. In the present case, because of the rarity of the lesion, we did not suspect a Tarlov cyst at first; however, the complete microsurgical excision resulted in a good outcome.

\section{Conflict of Interest}

No potential conflict of interest relevant to this article was reported.

\section{References}

1. Tarlov IM. Perineurial cysts of the spinal nerve roots. Arch Neurol Psychiatry 1938;40:1067-74.
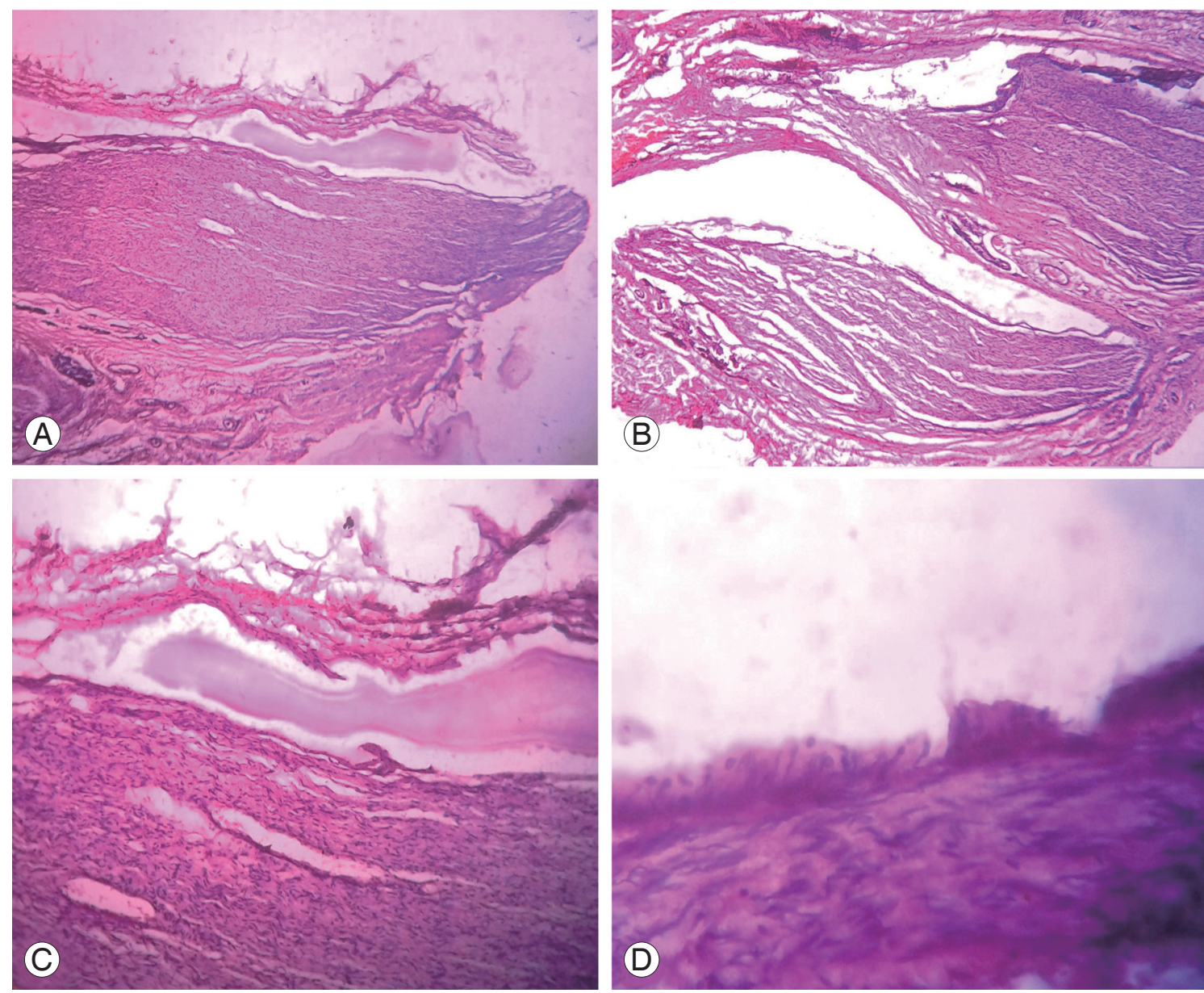

Fig. 3. (A) Section shows a cyst wall lined by flattened to cuboidal lining epithelium. The subepithelial tissue shows a nerve bundle and fibrocollagenous tissue with congested blood vessels (H\&E, $\times 50)$. (B) Section shows a cyst wall lined by flattened to cuboidal lining epithelium which is thrown into papillae in one foci. The subepithelial tissue shows a nerve bundle and fibrocollagenous tissue with congested blood vessels $(H \& E, \times 50)$. (C) Section shows a cyst wall lined by flattened to cuboidal lining epithelium which is thrown into papillae in one focus. The subepithelial tissue shows a nerve bundle and fibrocollagenous tissue with congested blood vessels $(H \& E, \times 100)$. (D) Section shows a cyst wall lined by low columnar epithelium with cells that have round to oval elongated nuclei. The subepithelial tissue showing a nerve bundle $(H \& E, \times 400)$. 
2. Sen RK, Goyal T, Tripathy SK, Chakraborty S. Tarlov cysts: a report of two cases. J Orthop Surg (Hong Kong) 2012;20:87-9.

3. Singh PK, Singh VK, Azam A, Gupta S. Tarlov cyst and infertility. J Spinal Cord Med 2009;32:191-7.

4. Chaiyabud P, Suwanpratheep K. Symptomatic Tarlov cyst: report and review. J Med Assoc Thai 2006;89:1047-50.

5. Bayrakli F, Kurtuncu M, Karaarslan E, Ozgen S. Perineural cyst presenting like cubital tunnel syndrome. Eur Spine J 2012;21 Suppl 4:S387-9.

6. Kim K, Chun SW, Chung SG. A case of symptomatic cervical perineural (Tarlov) cyst: clinical manifestation and management. Skeletal Radiol 2012;41:97101.

7. Seo JY, Ha KY. Chronic suppurative inflammatory cyst in the sacrum. Eur J Orthop Surg Traumatol 2012;22:5-8.

8. Goyal RN, Russell NA, Benoit BG, Belanger JM. In- traspinal cysts: a classification and literature review. Spine (Phila Pa 1976) 1987;12:209-13.

9. Tanaka M, Nakahara S, Ito Y, et al. Surgical results of sacral perineural (Tarlov) cysts. Acta Med Okayama 2006;60:65-70.

10. Paulsen RD, Call GA, Murtagh FR. Prevalence and percutaneous drainage of cysts of the sacral nerve root sheath (Tarlov cysts). AJNR Am J Neuroradiol 1994;15:293-7.

11. Tarlov IM. Spinal perineurial and meningeal cysts. J Neurol Neurosurg Psychiatry 1970;33:833-43.

12. Fortuna A, La Torre E, Ciappetta P. Arachnoid diverticula: a unitary approach to spinal cysts communicating with the subarachnoid space. Acta Neurochir (Wien) 1977;39:259-68.

13. Mummaneni PV, Pitts LH, McCormack BM, Corroo JM, Weinstein PR. Microsurgical treatment of symptomatic sacral Tarlov cysts. Neurosurgery 2000;47:748. 